\title{
Persistan Gestasyonel Trofoblastik Neoplazide Metotreksat Kullanımına Bağlı Nadir Görülen Kutanöz Ülserler: Olgu Sunumu
}

Rare Cutaneous Ulcers Related to Methotrexate Use in Persistant Gestational Trophoblastic Neoplasia: A Case Report

\author{
Alper SEYHAN ${ }^{1}$, Baki ERDEM ${ }^{1}$, Emel CANAZ ${ }^{1}$, Hakan GÜRASLAN ${ }^{1}$ \\ Ayşegül BESTEL ${ }^{1}$, Özgür AKBAYIR ${ }^{1}$
}

1. Kanuni Sultan Süleyman Eğitim ve Araştırma Hastanesi, Jinekolojik Onkoloji Kliniği, İstanbul, Türkiye

2. Bakırköy Dr. Sadi Konuk Eğitim ve Araştırma Hastanesi, Kadın Hastalıkları ve Doğum Kliniği, Istanbul, Türkiye

\section{$\ddot{O Z Z E T}$}

Giriş: Metotreksat; değişen rejim ve dozlarda çeşitli endikasyonlarda günümüzde yaygın kullanım alanı bulan, folik asit metabolizmasinı antagonize eden kemoterapotik ajandır. Kullanım alanları, başta romatolojik hastallklar olmak üzere, hematolojik maligniteler, gestasyonel trofoblastik neoplaziler ve bazı solid tümörleri içerir. Kullanım sırasında doz bağımlı ya da dozdan bağımsız olarak çeşitli toksik etkileri görülebilmektedir. Toksisiteyi önlemek için çeşitli medikasyonlar kullanılmaktadır. Ancak tüm koruyucu yaklaşımlara ră̆men kişisel ve genetik farklılıklar tedavi sonuçlarını etkilemektedir.

Olgu: 43 yaşında, persiste molar gebelik nedeniyle metotreksat rescue protokol uygulanan hasta sunulmuştur. Tedavi sırasında kutanöz ve oral ülserler görülmüş̧ür. Bu olgu sunumunda metotreksat tedavisi sırasında görülen toksik etkilerin yönetimi hakkında bilgi vermeyi amaçladık.

Sonuç: Kutanöz ve oral ülserler, persiste molar gebelik nedeniyle uygunan metotreksat tedavisi sirasında görülebilmektedir. Bu hastaların yönetiminde temel basamaklar; metotreksat tedavisinin kesilmesi, oluşan lezyonların sekonder enfeksiyonunun önlenmesi ve folinik asit desteğini kapsar.

Anahtar Kelimeler: metotreksat; kutanöz ülser; mukozit

\section{ABSTRACT}

Introduction: Methotrexate is a chemotherapeutic agent which inhibits the folate metabolism is a frequently used in different disease spectrum; malignancies (hematologic malignancies, solid tumors, gestational neoplastic diseases...) or non-malignant such as chronic inflammatory diseases or dermatologic diseases. While it's using, different toxic side effects can be seen which are dose-dependent or not. Different types of medications are used to prevent toxic side effects. Despite all preventive approaches, personal and genetic differences effect treatment results.

Case: We applied methotrexate rescue protocol for persistant molar pregnancy to 43 years old woman. During the treatment, cutaneus and oral ulcers were seen. With this case report, we want to give information about how to manage these toxic effects during the methotrexate treatment.

Conclusion: Cutaneus and oral ulcers are seen as a result of methotrexate treatment during persistant molar pregnancy. The basic steps in management of these patients; to stop methotrexate medication, to prevent seconder infections of cutaneus and oral ulcers and folinic acid supplement.

Keywords: methotrexate; cutaneus ulcers; mucositis

\section{İletişim:}

Sorumlu Yazar: Dr. Alper SEYHAN

Adres: Kanuni Sultan Süleyman Eğitim ve Araştırma Hastanesi Kadın Hastalıkları ve Doğum Kliniği, Türkiye

Tel: +90 (212) 4041500

E-Posta: alperseyhan@yahoo.com

Makale Geliş: 19.08.2015

Makale Kabul: 23.01.2016

DOI: http://dx.doi.org/10.16948/zktb.72592 


\section{GİRİŞ}

Metotreksat günümüzde yaygın olarak kullanılan folik asit metabolizması antagonisti bir kemoterapotik ajandır. Etki mekanizmasıyla ilişkili olarak malign hücre ya da dokuların yanısıra hızlı hücresel döngüsü olan normal vücut hücrelerine de etkisi nedeniyle yan etki profili belirgin olabilmektedir. Yan etkileri; gastrointestinal ve kemik iliği toksisitesi gibi doz bağımlı olabilirken, pnomonitis, karaciğer ve kardiak toksisiteler dozdan bağımsızdır (2).

$\mathrm{Bu}$ yazımizda persistan gestasyonel trofoblastik neoplazi nedeniyle metotreksat uygulanan hastada gelişen nadir gastrointestinal ve kutanöz toksisite bulguları sunulacaktır.

\section{OLGU}

43 yaşında bayan hasta, G5P3A2, bilinen hastalığ 1 olmayan, herhangi bir ilaç kullanımı (metotreksat ile etkileşme olasılığ sorguland1) olmayan hasta karın ağrısı ve adet gecikmesi nedeniyle acil jinekoloji polikliniğine başvurmuştur. B-hcg düzeyi 1073 olarak saptanmıştır. Şüpheli gestasyonel kese görülmesi nedeniyle 48 saat sonra b-hcg kontrolü yapılmış ve 1865 saptanmıştır. Erken gebelik ön tanısıyla hasta 20 gün sonra kontrole çağırılmiştır. USG kontrolünde bozulmuş fetal yapı ve hipertrofik plasenta izlenmiştir. B-hcg düzeyi 45.766 saptanmıştır. Hasta molar gebelik şüp- hesiyle jinekolojik onkoloji kliniğimize refere edilmiştir. Hastaya R/C yapılmış olup, patolojik tanı komplet molar gebelik olarak raporlanmıştır. 2 hafta sonraki b-hcg sonucu 409 olup, haftalik takibe alınmıştır. 1 hafta sonraki b-hcg:1202, 2.hafta 3235, 3.hafta 6157 olmas1 nedeniyle ve USG'de myometrial dokuya invazyon şüphesi olan ekojenik odak görülmesi nedeniyle persiste trofoblastik hastalık tanısıyla öncelikle evreleme amaçlı metastaz taraması yapılmıştır. Ekstrauterin odak saptanmaması nedeniyle ve Modifiye WHO prognostik skorlama Sistemine göre skoru $<7$ olması nedeniyle hastaya tek ilaç metotreksat-rescue protokol tedavisine karar verilmiştir. Hastaya 1, 3, 5, 7.günlerde $75 \mathrm{mg}$ metotreksat ve 2, 4, 6, 8. Günlerde $60 \mathrm{mg}$ folinik asit $(1 \mathrm{mg} / \mathrm{kg})$ uygulanmasına karar verilmiştir. Son metotreksat dozunu $(75 \mathrm{mg})$ aldığı gün yaygın oral ülseratif lezyonlar (Resim 1), oral beslenme olmaması ve her iki ayak parmaklarında yaygın deskuamasyonla birlikte ülsere alanlar eşlik eden lezyonlar (Resim 2) izlenmiştir.

Hastanın kan biyokimya değerleri görüldü. AST:45 ALT:40 BUN:12 KRE:0.8, hb:12.7, hct:35.3 trombosit:255 bin değerleri görüldükten sonra dermatoloji ve kbb poliklinik konsültasyonları yapılmıștır. Ayak parmaklarındaki lezyonlar skuamöz dermatit özelliğinde olup eroziv kandidiazis nedeniyle olabileceği düşünülerek, Travazol krem $2 * 1$ ve Funit tablet $2 * 2 / 7$ gün önerilmiştir. Hasta 3 gün takip edilmiştir.

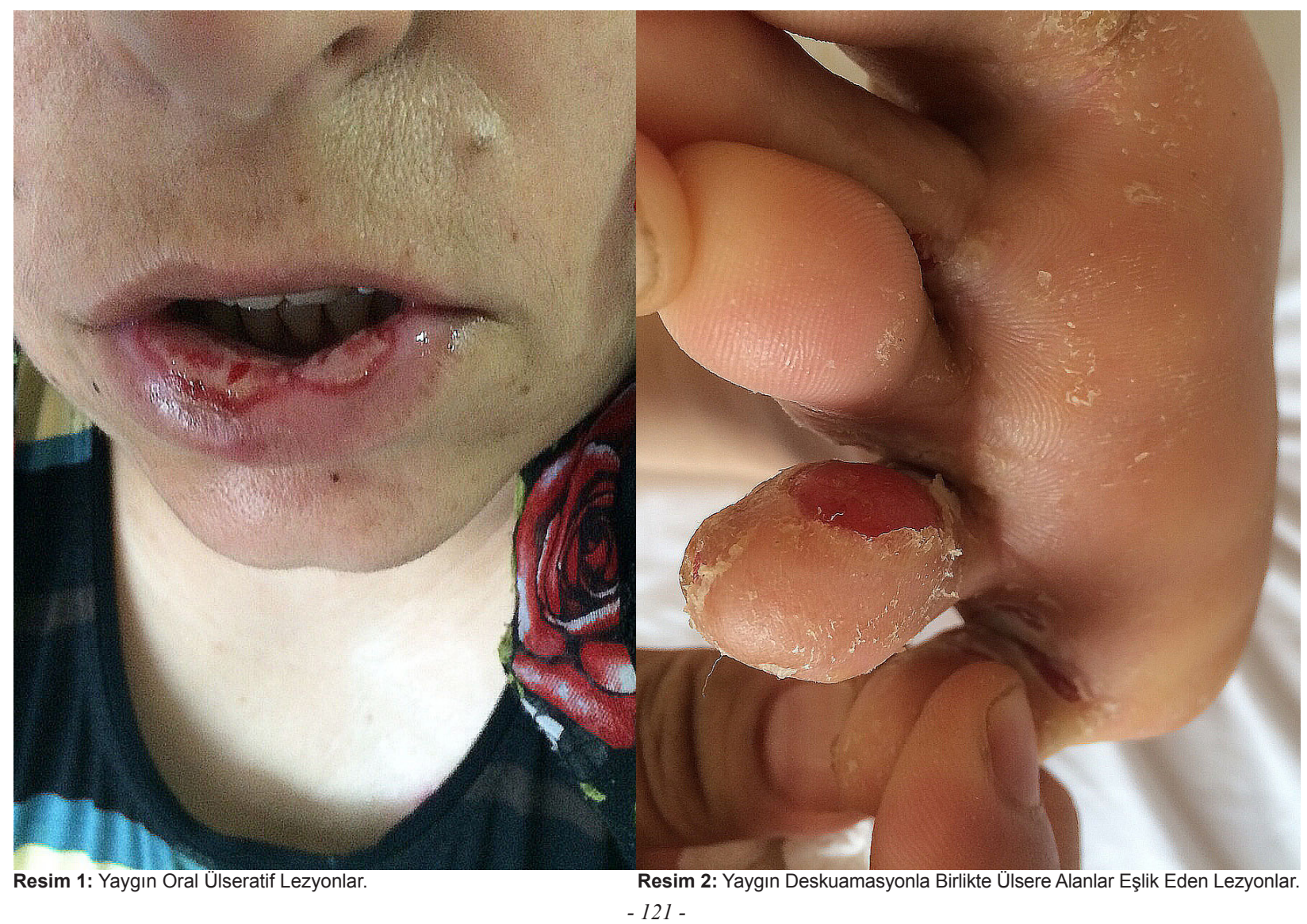



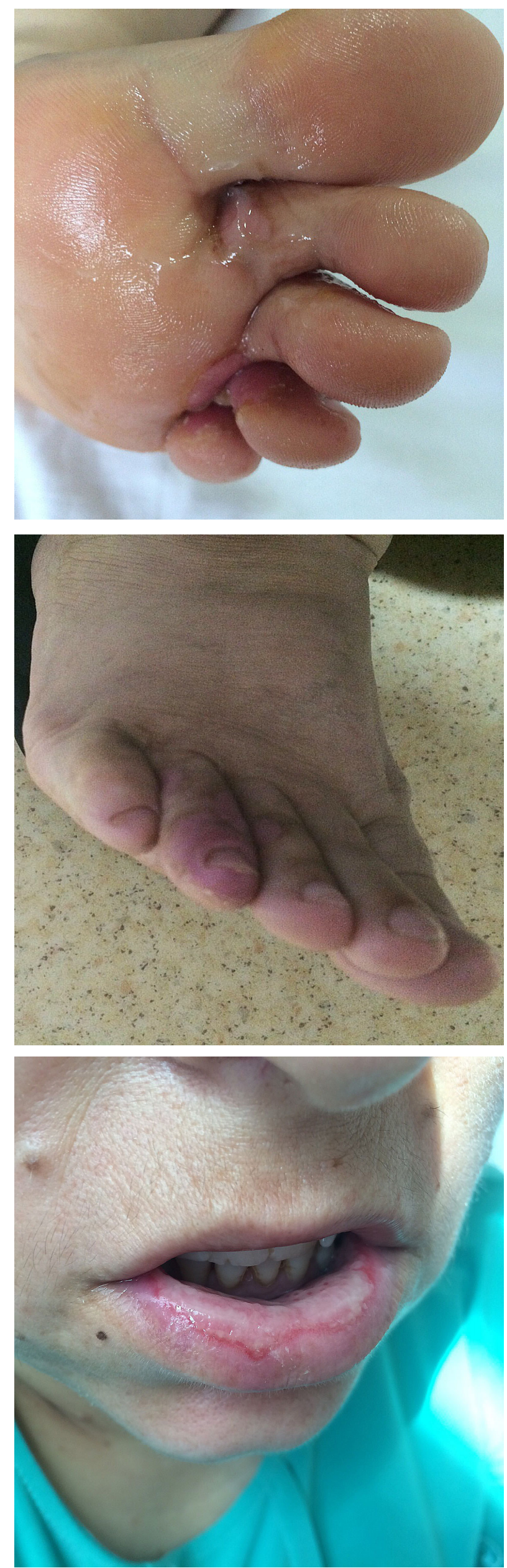

Resim 3, 4, 5: Gerileyen Mukoza ve Cilt Lezyonları.
Oral alım kısıtlılığ edilmiştir. Genetik pleomorfizmler olabilmesi nedeniyle hastaya 3 gün süreyle folik asit $5 \mathrm{mg}$ oral tb verilmiştir. 2. günde lezyonları gerilemesi üzerine sıv1 gida ve suyla beslenmeye geçilmiştir. 3. günde cilt lezyonları da gerilemesi üzerine mevcut tedavisi ile taburcu edilmiştir. Hasta 5 gün arayla iki kez kontrole çağırılmıştır (Resim 3, 4, 5). Lezyonların tamamen gerilediği gözlenmiş olup, hastanın tedavi sonrası ilk hafta b-hcg düzeyi 126 olması üzerine ek doz metotreksat düşünülmemiştir. Haftalık takiplerde 3 hafta sonra bhcg düzeyi 0.2 , takip eden 2 hafta daha 0.5 ve 0.1 değerleri görülmüş olup, hastanın kan değerlerinde pansitopeni ya da biyokimyasal parametrelerde olumsuz durum olmaması üzerine hasta aylık b-hcg takiplerine çağırılmıştır.

\section{TARTIŞMA}

Persistan Gestasyonel Trofoblastik Neoplazi'lerdeki metotreksat uygulamalarında oluşabilen toksisiteler ile ilgili çalışmalar yok denecek kadar azdir. 1950'lerde metotreksat prekürsörü Aminopterin'in Romatoid Artrit'te kullanıma girmesiyle romatolojik hastalıklarda geniș kullanım alanı bulmuș olup, etkinlik ve yan etki çalışmaları çoğunlukla romatolojik hastalıklar yönünde ilerlemiştir. Metotreksat'ın moleküler etki mekanizmaları incelenerek etki ve yan etkileri daha net anlaşılmaktadır. Öncelikle dihidrofolat redüktazı inhibe eden bir folik asit analoğudur ve pürin-pirimidin sentezinin baskılanmasına yol açar (4). Diğer yandan timidilat sentetaz, amino-imidazolkarboksiamid ribozil-5 fosfat(AICAR) transformilaz inhibisyonu ve homosistein'in metionin'e dönüşüm inhibisyonu nedeniyle pürin-pirimidin sentezi azalır, biriken homosistein hücrede adenozin salınımına neden olarak immün süpresif ve anti-inflamatuar mediatör etkisine neden olur (2). Metotreksat toksisitesi üç ana grupta incelenir. Birinci grup, direkt gastrointestinal ve kemik iliği toksisitesi olup, doz bağımlıdır. Ancak plazma ilaç konsantrasyonu ile toksik etki korelasyonu kesin olarak saptanmamıştır (3). İkinci grup, alerjik toksisite olup, akciğerde pnömonitis tablosu buna örnektir. Üçüncü grup, uzun dönem tedaviye bağlı özellikle hiperhomosisteinemiye bağlı karaciğer ve kardiak hastalıklardir.

Olgumuzda yer alan bulantı ve stomatit gibi gastrointestinal yan etkileri yüksek doz metotreksat kullanımında belirgin olmasına rağmen her dozda görülebilen ancak doza bağ11 yan etkilerdir. Birbiri ile ilişkili 18 çalışmanın sonuçlarına göre düşük doz metotreksat 
tedavisi nedeniyle stomatit gelişme oranı \%14 saptanmıştır. \%3 hastada yan etkiler nedeniyle tedavi yarıda kesilmiştir (3). Ince ve ark. Romatoid artrit nedeniyle uzun dönem düșük doz metotreksat alan hastalarda \%37.2 stomatit saptamıştır (kontrol grubunda \%19.5 p<0.01). Lezyonların \%15.7'si 1 aydan uzun sürerken, \%31.5'i 1 hafta kadar sürmüștür.Folik asit replasmanı yapılmamıştır (5). Khan ve ark. Yaptığ 1 çalışmada, düşük riskli persistan gestasyonel trofoblastik neoplazi' de düșük doz metotreksat etkinliği ve yan etkileri araştırılmış ve ilk tedavi protokolü denemesinde \%24.4 stomatit saptanmıştır (6). Ruperto ve ark. Çalışmasında olduğu gibi birçok çalışmada oral lezyonların prevalansı ile ilaç dozu arasında korelasyon saptanmamıştır (7). Olguda yer alan alt ekstremite parmak uçlarındaki kutanöz ülserler litaratürde son derece nadir görülmektedir. Psöriazis gibi daha önceden var olan cilt lezyonları üzerinde ülser ya da benzeri lezyonlar gelişmesi kapsam dışı bırakılırsa, primer cilt lezyonuna çok nadir rastlanmaktadır. Psöriazis gibi deskumasyonla ve proliferasyonla seyreden lezyonlarda hücresel döngünün hızlı olması ve metotreksat tutulumunun fazla olması lezyonlar üzerinde yan etki görülme olasılığını artırmaktadır. Primer metotreksat ilișkili oluşan lezyonlarda etkili olduğu düşünülen mekanızma, keratinosit yüzeylerinde ilaç-derive antijenlerin bulunması ve sitotoksik-T lenfositlerin apoptozisi indüklemesi sonucu oluşmaktadır. Bizim olgumuzda ise, daha önce bilinen lezyonları olmayan hastada büllöz ve eroziv karakterdeki lezyonların sekonder eroziv kandida enfeksiyonu geliştirdiği görülmüştür. Mukozal ve kutanöz lezyonların sekonder infeksiyon açısından tetkik edilmesi önemlidir. Metotreksat toksisitesi nedeniyle oluşan stomatit ya da kutanöz lezyonlarda $\% 70$ 'lere varan oranda en s1k etken Kandida'dır. Temel neden mukozal ve cilt bariyerinin bozulmasi olsa da, metotreksat ve mevcut hastalıkların oluşturduğu immünsüpresif etki önemlidir.

Olguya rutin mtx-rescue protokol dișinda 4 gün süreyle $4 \mathrm{mg}$ folik asit desteği verilmiştir.Folik asit ve indirgenmiş formu folinik asit mukozal toksisiteyi azaltmada en etkin ve ucuz yöntemdir (8). Bir cochrane derlemesinde folik asit ya da folinik asit hastalık aktivitesini etkilemeden mukozal toksisiteyi azaltmıştır (9). Folinik asit, dihidrofolat redüktaz enzim basamağına ihtiyaç duymadığı için ve hücre içine alınırken metotreksat ile yarıştığ 1 için klinik etkisi folik aside karşı üstündür. Yan etki oluşması durumlarında Folik asit desteğinin hangi dozda olması tartışmalıdır. Genel görüş 1-5 mg/ gün düzeyidir.

\section{SONUÇ}

Persistan gestasyonel trofoblastik neoplazilerde(GTN) metotreksat kullanımı sonucu gelişen toksisiteler ile ilgili literatür son derece k1sitlıdır. Elde edilen bilgiler uzun dönem düşük doz metotreksat verilen romatolojik hastalıklar ile yüksek doz metotreksat kullanılan malignitelerle sinırlıdır. Persistan GTN'lerde kullanılan metotreksat tedavi protokollerinin çok değişken uygulanıyor olmasi ve hasta grupları arasındaki heterojenite,bu konuda konsensüs oluşturulmasinı engellemektedir (10). Çalıșmaların diğer bir kısitlılığ1 ise, ilaç toksisitesinde hastaya ait değişken faktörlerin standardize edilmesindeki güçlüktür. Hastanın kullandığı anti-inflamatuar ilaçların ve antibiyotiklerin metotreksat metabolizma ve atılımını etkilemesi, folik asit metabolizmasındaki genetik polimorfizmler değişkenlerin sadece bir kısmıdır.

\section{$K A Y N A K L A R$}

1. Mc Kendry RJ. The remarkable spectrum of methotrexate toxicities. Rheum Dis Clin North Am 1997;4:939-54.

2. Van Ede AE, Laan RF, Blom HJ, De Abreu RA. van de Putte LB. Methotrexate in rheumatoid arthritis: an update with focus on mechanisms involved in toxicity. Semin Arthritis Rheum 1998; 5:277-92.

3. Cutolo M, Sulli A, Pizzorni C, Seriolo B, Straub RH. Antiinflammatory mechanisms of methotrexate in rheumatoid arthritis. Ann Rheum Dis 2001;8:729-35.

4. Athanasios Kalantzis, DDS, MFDS, Zoe Marshman, BDS, MPH, MFDS, DDPH, Denis T. Falconer, BChD, FDSRCS, $M B C h B, F R C S$, Peter R. Morgan, BDS, BSc, PhD,FRCPath, FDS, and Edward W. Odell, BDS, FDSRCS, MSc, PhD, FRCPath, London, Sheffield, and Romford, UK. Oral effects of low-dose methotrexate treatment: Oral Surg Oral Med Oral Pathol Oral Radiol Endod 2005; 100:52-62

5. Ince A, Yazici Y, Hamuryudan V, Yazici $H$. The frequency and clinical characteristics of methotrexate (MTX) oral toxicity in reumatoid arthritis (RA): A masked and controlled study. Clin Rheumatol 1996;15: 491-494.

6. Khan F, Everard J, Ahmed S, Coleman RE, Aitken M, Hancock $B W$. Low-risk persistent gestational trophoblastic disease treated with low-dose methotrexate: efficacy, acute and long-term effects:Br J Cancer 2003;15;89(12): 2197-201

7. Ruperto N, Murray KJ, Gerloni V, Wulffraat $N$, de Oliveira $S K$, Falcini, $F$ et al. A randomized trial of parenteral methotrexate comparing an intermediate dose with a higher döse in children with juvenile idiopathic arthritis who failed to respond to standard doses of methotrexate. Arthritis Rheum. 2004 Jul;50(7):2191-201.

8. Alarcon GS. Methotrexate: its use for the treatment of rheumatoid arthritis and other rheumatic disorders. In: Koopman W, editor.rthritis \& allied conditions. A textbook of rheumatology. 13th ed. London: Williams and Wilkins; 1997.p. 679-98.

9. Ortiz Z, Shea B, Suarez Almazor M, Moher D, Wells G, Tugwell $P$. Folic acid and folinic acid for reducing side effects in patients receiving methotrexate for rheumatoid arthritis. Cochrane Database Syst Rev 2000;2:CD000951.

10. Gilani MM, Yarandi F, Eftekhar Z, et al. Comparison of pulse methotrexate and pulse dactinomycin in the treatment of low-risk gestational trophoblastic neoplasia. Aust N Z J Obstet Gynaecol 2005; $45: 161-4$. 